\title{
Assessment of DNA and mtDNA Degradation in Sperm Cells Collected by Laser Micro-dissection
}

\author{
Costa $\mathbf{S}^{1,2^{*}}$, Lima $\mathbf{G}^{2}$, Correia-de-Sa $\mathrm{P}^{3}$, Porto $\mathbf{M J}^{2}$ and Caine $\mathbf{L}^{1,2}$ \\ ${ }^{1}$ Department of Legal Medicine and Forensic Sciences, Faculty of Medicine, University of Porto, Portugal \\ ${ }^{2}$ National Institute of Legal Medicine and Forensic Sciences, North Department, Oporto, Portugal
}

${ }^{3}$ Laboratory of Pharmacology and Neurobiology, Center for Drug Discovery and Innovative Medicines (MedlnUP), Instituto de Ciencias Biomédicas de Abel Salazar (ICBAS), Universidade do Porto (UP), Portugal

"Corresponding author: Sergio Costa, Forensic Biology and Genetic Service, North Department of the National Institute of Legal Medicine and Forensic Sciences Jardim carrilho Videira, S/n Porto 4050167, Portugal, Tel: +351222073850; E-mail: sergiospcosta@gmail.com

Received date: October 10, 2017; Accepted date: October 18, 2017; Published date: October 23, 2017

Copyright: (c) 2017 Costa S, et al. This is an open-access article distributed under the terms of the Creative Commons Attribution License, which permits unrestricted use, distribution, and reproduction in any medium, provided the original author and source are credited.

\begin{abstract}
Sexual assault samples are among the most frequently analyzed in a forensic laboratory. These accounts for almost half of all samples processed routinely and a large portion of these cases remain unsolved. These samples often pose problems to traditional analytic methods of identification because they consist most frequently of cell mixtures from at least two contributors: the victim (usually female) and the perpetrator (usually male). In this study we prepared simulated sexual assault samples and conducted amplification and DNA genotyping from sperm cells collected with laser microdissection at different time intervals to assess the DNA degradation at those intervals. Furthermore, we then investigated the possibility of recovering mtDNA from the collected sperm cells, particularly in cases where autosomal DNA was not suitably amplified. With this work we determined that it becomes possible to extend the timeframe for performing an analysis, by researching other sources of DNA, namely mtDNA.
\end{abstract}

Keywords Forensic; Sexual assault; Laser microdissection; Sperm; mtDNA; Degraded sample

\section{Introduction}

Forensic casework consists, among other tasks, in solving sexual assault cases. Most of these cases are perpetrated by a male unknown individual, and the victim is a female [1]. The sexual samples to analyze involve of a mixture between these two contributors. The male portion consists mainly of semen, whereas the female contribution is mainly epithelial cells. For successfully solving these cases, forensic laboratories must resolve the individual profiles from both victim and perpetrator. This can be achieved either by performing separation of the different fractions in the mixture sample, with the commonly used differential extraction procedure [2] or less common laser microdissection [3] or by analyzing the whole sample and statistically resolving the individual genetic profiles from a mixture result.

However, collecting biological samples beyond 72 hour after the occurrence greatly diminishes the chances of recovering the DNA profile from the perpetrator [4]. Sperm cells start lysing and the DNA becomes increasingly degraded, rendering an analysis impossible.

Although autosomal DNA becomes rapidly degraded, mtDNA is more resistant. This small, circular genome is found in the mitochondria, small organelles that are present in every cell. With multiple copies of mtDNA in each mitochondrion and several mitochondria per cell, the amount of mtDNA copies per cell far exceeds the single copy of autosomal DNA in the cell. Furthermore, the double membrane of the mitochondrion and the circular structure (without open ends) of mtDNA act as protective agents against the degradation processes. For these reasons, in cases with old and degraded samples mtDNA can be the single, recoverable DNA profile
[5]. In sperm cells, mitochondria are located in the middle piece of the cell, between the sperm head and its tail.

With this work we aimed to investigate the possibility of recovering mtDNA from laser microdissected sperm cells, beyond the 72 hour mark, in experimental mixtures.

\section{Material and Methods}

Six experimental samples were prepared using $200 \mu \mathrm{l}$ of semen and $800 \mu \mathrm{l}$ of female saliva. The samples were left to incubate at room temperature and $50 \mu \mathrm{l}$ aliquots were collected at different time intervals: 48 hour, 72 hour, 96 hour and 144 hour. Samples were collected under informed consent from two healthy volunteers. The study was approved by the Ethics Committee of the National Institute of Forensic Medicine and Forensic Sciences, IP and the Health Ethics Committee of the Hospital Center of Sao Joao.

The aliquots were then smeared onto a microscopic slide, with a special PET membrane (polyethylene terephthlatate) (MMI membrane slide) and fixated with alcohol 95\% (v/v). The Sperm Hy-Liter Express (Independent Forensics) (SHL) was used to stain the samples according to the manufacturer's instructions, except for the final (optional) mounting procedure. Nuclei from both epithelial and sperm cells were visualized using DAPI-compatible fluorescence filters. Human sperm heads were visualized using fluorescein or Alexa 488 compatible filters.

\section{Laser microdissection}

Laser microdissection was conducted in an Olympus Cell Cut Inverted Microscope with a fluorescence module attached. The MMI Cell Tools ${ }^{\oplus}$ software was used to command visualization, microdissection, capturing and reporting cells of interest. The 
procedure included a full slide scan for each slide with a $4 \mathrm{X}$ objective. Cutting was performed with the 20X objective for Sperm Hy-Liter stained samples. Microdissected sperm cells were automatically captured (glued by the mounting membrane) directly onto MMI Isolation Caps of $0.5 \mathrm{ml}$ microtubes without any kind of manipulation, thus preventing sample contamination by the operator. Approximately 500 sperm cells were selected to be captured per slide. Captured sperm cells were microscopically inspected whenever necessary during the procedure to confirm integrity and relative position of the samples on the MMI Isolation Cap.

\section{DNA extraction}

Extraction was performed using the Arcturus PicoPure DNA Extraction kit (Applied Biosystems - USA). This extraction kit was selected because it was specifically designed for LMD samples and provides a DNA yield of up to $100 \%$ in such samples. The portion of the cap where cells were present was removed with a sterile scalpel blade and placed into a $0.2 \mathrm{ml}$ microtube containing $40 \mu \mathrm{l}$ of the extraction solution. The samples were incubated for 3 hour at $65^{\circ} \mathrm{C}$ and the proteinase $\mathrm{K}$ was inactivated at $95^{\circ} \mathrm{C}$ for 10 minutes.

\section{DNA amplification and genotyping}

Autosomal DNA was amplified using GlobalFiler PCR Amplification Kit (Applied Biosystems - USA). Each sample was amplified using 3,75 $\mu \mathrm{l}$ of Master Mix, $1.25 \mu \mathrm{l}$ of primer set, $2 \mu \mathrm{l}$ of DNA and $5.5 \mu \mathrm{l}$ of TE (Tris-EDTA) buffer. Thermal cycling was performed on GeneAmp 9700 Thermal Cycler (Applied Biosystems USA), with initial incubation of 1 minutes at $95^{\circ} \mathrm{C}, 29$ cycles of denaturation (10 second at $94^{\circ} \mathrm{C}$ ) and annealing/extension ( 90 second at $59^{\circ} \mathrm{C}$ ) and a final extension of 10 minutes at $60^{\circ} \mathrm{C}$. For mtDNA, amplification was performed for the HV1 region, with a nested PCR. Successful fragment amplification was verified with the use of a QIAxcel Advanced (Qiagen). mtDNA samples were amplified using 10 $\mu \mathrm{l}$ of Taq Plus (Qiagen) Master mix, $0.5 \mu \mathrm{l}$ of forward primer, $0.5 \mu \mathrm{l}$ of reverse primer, $2 \mu \mathrm{l}$ of sample DNA and $7 \mu \mathrm{l}$ of amplification grade water.

Primers used in the reactions were: F15989 (CCCAAAGCTAAGATTCTAAT) and R16443 (TTGTGCGGGATATTGATTTCAC) for the first amplification (HV1). Amplification settings were a first incubation step of 5 minutes at $95^{\circ} \mathrm{C}$, followed by 40 cycles of denaturation $\left(95^{\circ} \mathrm{C}\right.$ for 45 second) primer annealing $\left(58^{\circ} \mathrm{C}\right.$ for 1 minutes) and elongation $\left(72^{\circ} \mathrm{C}\right.$ for 1 minutes) and lastly a $72^{\circ} \mathrm{C}$ for 10 minutes final elongation step. DNA was then treated with ExoSAP $(5 \mu \mathrm{l})\left(37^{\circ} \mathrm{C}\right.$ for 40 minutes and $80^{\circ} \mathrm{C}$ for 20 minutes). The nested amplifications were performed using F15989 (CCCAAAGCTAAGATTCTAAT) with R16248 (GTTGCAGTTGATGTGTGATAG) for the first half of the HV1 region (HV1-a) and F16094 (TCGTACATTACTGCCAGYC) with R16443 (TTGTGCGGGATATTGATTTCAC) for the second half of the HV1 region (HV1-b). Samples were again treated with $5 \mu \mathrm{l}$ of ExoSAP. All thermocycling operations and sequencing reactions were carried out in a 9700 thermocycler (Applied Biosystems).

Mitochondrial DNA sequencing reactions were performed with the BigDye v3.1 amplification kit from Applied Biosystems ${ }^{\oplus}$ using the above mentioned primers for HV1-a and HV1-b. The reaction was executed using $1.5 \mu \mathrm{l}$ of Master Mix, $1 \mu \mathrm{l}$ of primer, $2 \mu \mathrm{l}$ of amplified sample and $5.5 \mu \mathrm{l}$ of amplification grade water, under the following conditions: 25 cycles of denaturation $\left(96^{\circ} \mathrm{C}\right.$ for 10 second) and primer annealing $\left(50^{\circ} \mathrm{C}\right.$ for 5 second) and extension $\left(60^{\circ} \mathrm{C}\right.$ for 4 minutes). After the amplification samples were treated (to remove unincorporated bye terminators and salts) with BigDye XTerminator ${ }^{\otimes}$ Purification Kit, according to the manufacturer instructions.

Autosomal DNA samples were prepared for capillary electrophoresis using $0.5 \mu \mathrm{L}$ of fifth dye-labeled size standard (GeneScanTM Liz 600 Size Standard), $12.5 \mu \mathrm{L}$ of Higly Deionizied Formamide (Hi-Di ${ }^{\mathrm{ma}}$ Formamide) (Applied Biosystems - USA), and 1 $\mu \mathrm{L}$ of sample or GlobalFiler allelic ladder. Injection conditions for the 3500 Genetic Analyzer (Applied Biosystems - USA) used $1.2 \mathrm{kV}$ and 12 seconds for injection. The analysis employed a minimum threshold of 15 RFU for the 3500 Genetic Analyzer, using the GeneMapper ID-X v1.2 analysis software. Mitochondrial DNA sequencing analysis was performed in a 3130xl Genetic Analyzer, using $10 \mu \mathrm{l}$ of sample and 6 $\mu \mathrm{L} \mathrm{Hi}-\mathrm{Di}^{\mathrm{m}}$ formamide. Results were analyzed using Sequencing v5.4 and SeqScape v3.

\section{Results}

Amplification with the GlobalFiler kit was performed to determine the recoverability of male autosomal DNA at different time intervals. At 48 hour, DNA quality is already very low, but a full profile was recovered.

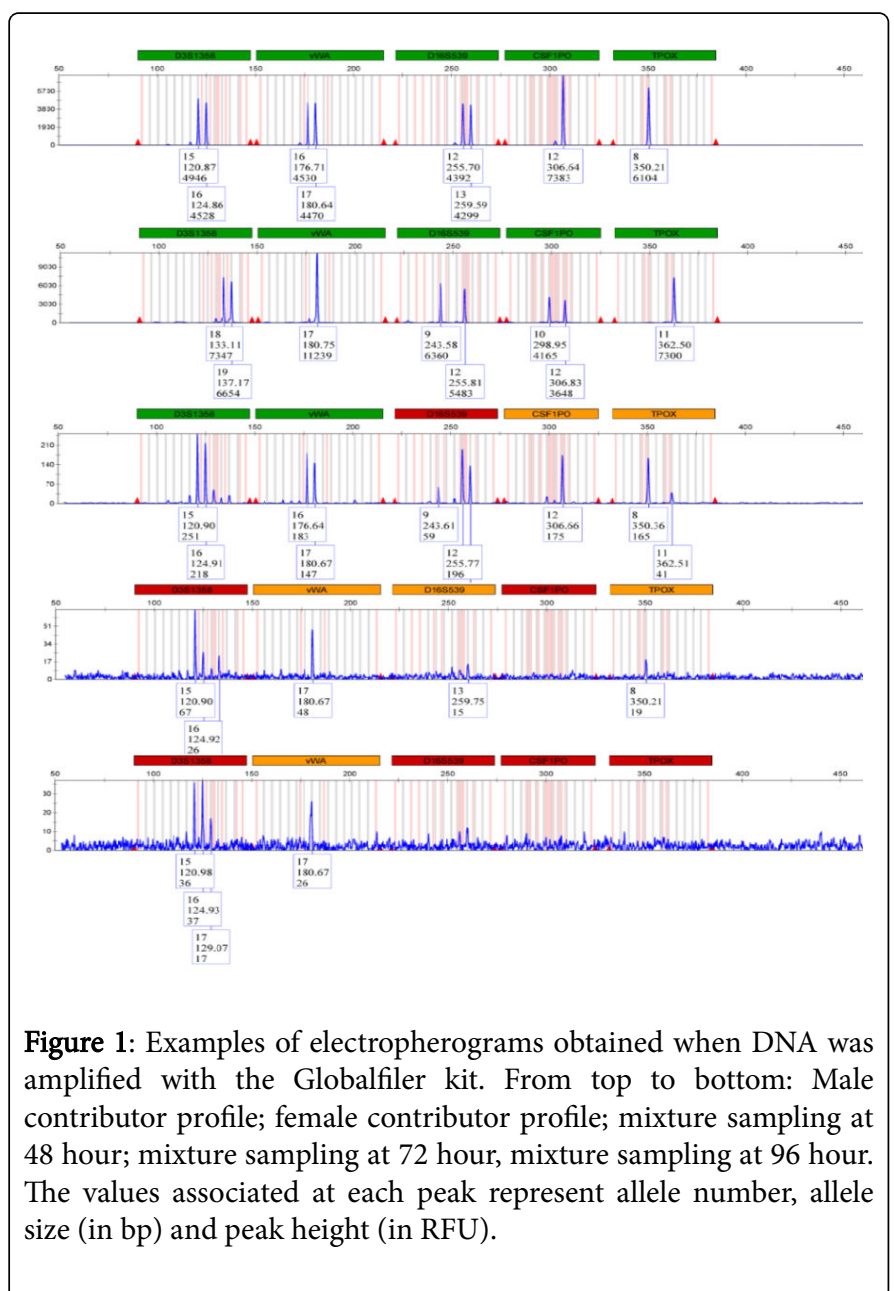

However, due to stochastic effects, low template DNA available and contamination from the female contributor, a mixture appears at 
certain loci. At 72 hour some loci and some alleles begin to drop-out. Only the combination of multiple samples allowed the recovery of a complete male profile. 96 hour after the mixture preparation, there is a lack of results at multiple loci, particularly the ones that are the result of amplification of longer fragments. Finally, after 144 hour, no amplification was obtained (Figure 1). These results are consistent to what is described in the literature [6,7] and provide some context to the following analysis of mtDNA recovered from the sperm cells.

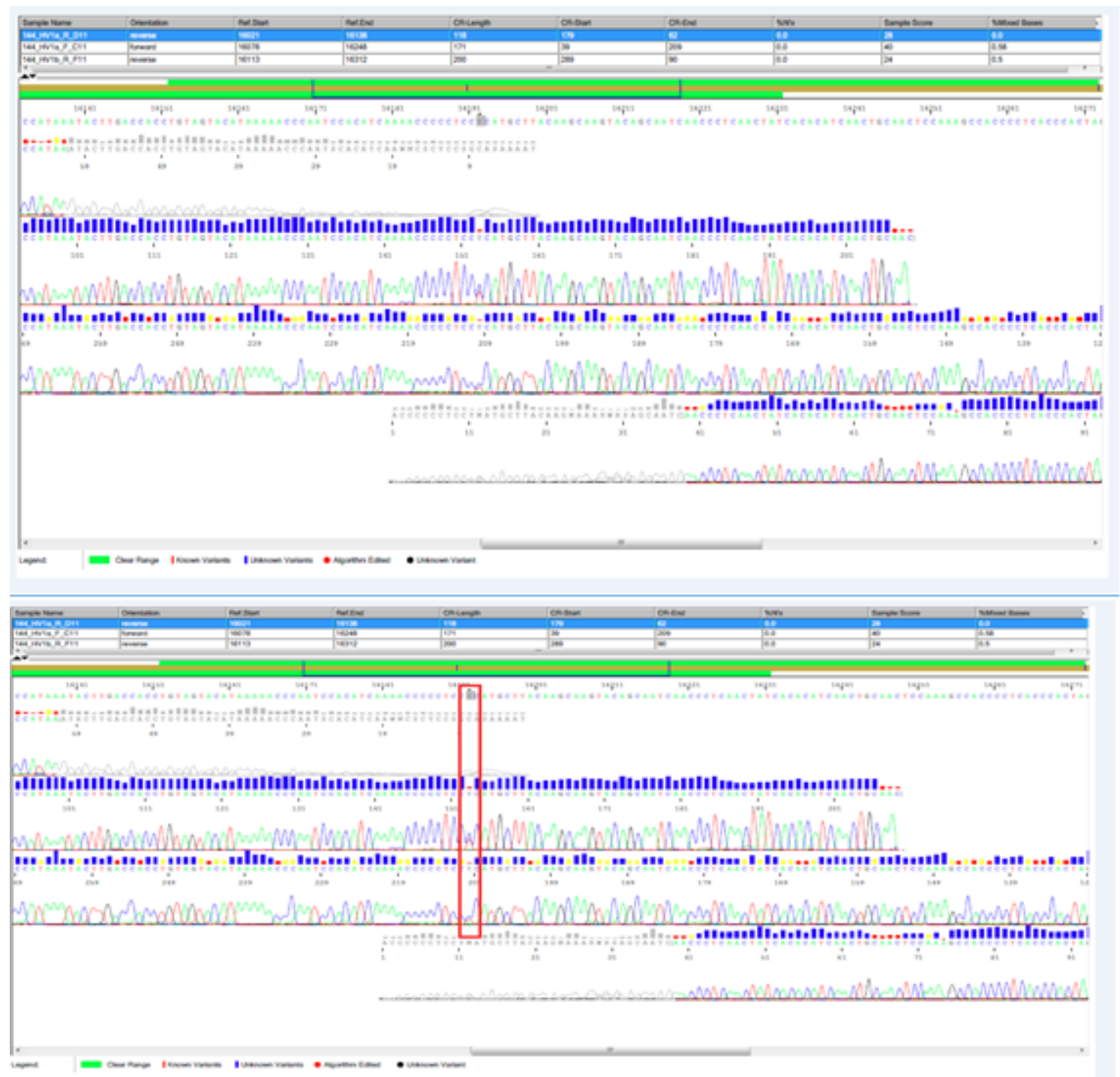

Figure 2: Results obtained by amplification and sequencing of mitochondrial DNA. Heteroplasmy was found in the position 16192, marked in red.

Mitochondrial DNA extraction and nested HV1 sequencing yielded results all the way up to 144 hour after the sample preparation. The only mutation found in the HV1 region was a heteroplasmy in the position $16192 \mathrm{C}>\mathrm{Y}$, when compared to the Revised Cambridge Reference Sequence (rCRS) (figure 2). Sample donors have different haplotypes and the found haplotype belongs to the male contributor.

\section{Discussion and Conclusions}

With this work we aimed to prove the feasibility of amplifying mtDNA from sperm cells collected by laser microdissection. We used the GlobalFiler amplification kit to ensure the correct amplification of autosomal DNA. The results obtained are according to the described in the literature: after 72 hour, obtaining a complete male genetic profile from a mixture sample is almost impossible. In those cases, mtDNA recovery and amplification can be an alternative, in order to obtain some genetic information regarding the perpetrator of a sexual assault. Exploratory work was performed to determine if other regions of the mtDNA chain could be successfully amplified. Our results show that HV2 and HV 3 can also be recovered.

Straight-forward exploratory amplification of HV1 fragments was achieved with mixed results in all cases. When confirming the amplification with the QIAxcel, some fragments returned a good amplification signal while some samples returned a weaker signal. This happened mainly because we were working with low template DNA. In 
Citation: Costa S, Lima G, Correia-de-Sa P, Porto MJ, Caine L (2017) Assessment of DNA and mtDNA Degradation in Sperm Cells Collected by

Page 4 of 4

those situations, even with DNA of good quality, some amplifications may not yield any results due to stochastic effects. Nevertheless, DNA was not in sufficient quantity to immediately perform the sequencing analysis. In order to increase the amount of DNA for analysis and further purify it, we opted to perform a second, nested PCR.

A nested PCR greatly increased the number of available fragments for analysis and sequencing results were obtained 144 hour after the experimental mixture sample preparation.

With this work we determined that it is possible to recover some genetic information from biological samples, namely sexual assault cases, beyond 72 hour after the occurrence. DNA may be degraded beyond possible salvage of any autosomal marker, but other markers may be retrieved, such as mtDNA or even SNPs (Single Nucleotide Polymorphisms). Good separation techniques prior to DNA amplification or even extraction must be in place in order to resolve male and female contributions. Failure to do so may result in obtaining uninterpretable mixture profiles.

\section{References}

1. Amar AF, Sutherland M, Laughon K (2014) Gender Differences in attitudes and beliefs associated with bystander behavior and sexual assault. J Forensic Nurs 10: 84-91.

2. Gill P, Jeffreys AJ, Werrett DJ (1985) Forensic application of DNA 'fingerprints'. Nature 318: 577-579.

3. Emmert-Buck MR, Bonner RF, Smith PD, Chuaqui RF, Zhuang Z, et al. (1996) Laser capture microdissection. Science 274: 998-1001.

4. Magalhaes T, Dinis-Oliveira RJ, Silva B, Corte-Real F, Nuno Vieira D (2015) Biological evidence management for DNA analysis in cases of sexual assault. The Scientific World Journal.

5. Sullivan KM, Hopgood R, Lang B, Gill P (1991) Automated amplification and sequencing of human mitochondrial DNA. Electrophoresis.12: 17-21.

6. Gomes V, Jardim P, Taveira F, Dinis-Oliveira RJ, Magalhães T (2014) Alleged biological father incest: A forensic approach. J Forensic Sci 59: 255-9.

7. Burg A, Kahn R, Welch K (2011) DNA testing of sexual assault evidence The laboratory perspective. J Forensic Nurs 7: 145-52. 